\title{
A COMPARATIVE STUDY OF THE GRADIENT ACCOMMODATIVE CONVERGENCE/ACCOMMODATION RATIOS OBTAINED THROUGH +1.00DS AND -1.00DS IN PRIMARY SCHOOL CHILDREN
}

\author{
BY \\ *AMAECHI, O. U. AND OBIORA, I. \\ DEPARTMENT OF OPTOMETRY, \\ ABIA STATE UNIVERSITY \\ UTURU, ABIA STATE, NIGERIA \\ Email:okamaechi@yahoo.com \\ *Corresponding author
}

\section{ABSTRACT}

The gradient accommodative convergence/accommodation ratios (AC/A ratios) of fifty healthy primary school children between the ages of 6-12 years determined through a $+1.00 \mathrm{DS}$ lens and through a $-1.00 \mathrm{DS}$ lens were compared. This was done by measuring the induced phoria at near using the Von Graeffe technique and subsequently through a +1.00DS lens and a -100DS lens; the change in phoria brought about by the change in stimulus to accommodation gave the value of the gradient AC/Aratio. The mean $\mathrm{AC} / \mathrm{A}$ ratio through $+1.00 \mathrm{DS}$ was $3.4 \pm 1.4$ and through $-1.00 \mathrm{DS}$ was $4.2 \pm 2.0$. The difference in the two $\mathrm{A} / \mathrm{C}$ ratios was found to be significant $(\mathrm{P}<0.05)$. It is recommended that borderline patients should have their gradient $\mathrm{AC} / \mathrm{A}$ ratio checked through both lenses for more precise diagnosis and management.

KEYWORDS: Accommodation, Convergence, Gradient accommodative convergence/accommodation ratio, Induced phoria, von Graeffe technique.

\section{INTRODUCTION}

Accommodation is an increase in the optical power by the eye in order to maintain a clear images as objects are moved closer, and convergence is the inward movement of both eyes towards each other, usually in an effort to maintain single binocular vision as an object approaches. Accommodation and convergence therefore have to work harmoniously for clear single binocular vision to be achieved. Accommodation and convergence have a synkinetic relationship, which ensures that clear, stable, single binocular vision is present across a range of viewing distances. When accommodation (A) is exerted, the eyes are induced to converge which is known as accommodative convergence (AC), because the muscles involved in the two situations get their nerve supply from the oculo-motor nerve (Cranial nerve II).

Accommodative convergence/ accommodation ratio (AC/Aratio) is the amount of accommodative convergence measured in prism dioptres (æ per unit change in accommodation measured in dioptres (D) ${ }^{2,3}$. There are slight variations in the normal range of AC/A ratios as reported by some authors thus: $3 / 1$ to $5 / 1^{4}, 4 / 1$ to $5 / 1^{2}$, and $4 / 1$ to $6 / 1^{3}$. The ACA ratio remains constant for an individual and varies among individuals. A high AC/Aratio maybe indicative of a convergence excess problem or latent hyperopia which indicates that the patient depends on his accommodation for convergence. A low AC/A ratio maybe indicative of a convergence insufficiency or a convergence weakness problem, which means that the patient does not depend on his accommodation for convergence. Knowledge of the AC/Aratio can be useful when determining lens power for the optical correction of convergence problem ${ }^{5,6}$

Children of primary school age (6-12 years) are in the active stages of growth and development and they engage in near point activities, and for these to be possible without asthenopic symptoms, a balance between accommodation and convergence must be maintained. In binocular vision case analysis, accommodative convergence must be maintained. In binocular vision case analysis, accommodation convergence effort exerted by an individual helps to either maintain single binocular vision and he will enjoy visual efficiency in which case the AC/Aratio is normal or abnormal wherever there is convergence insufficiency (low AC/A ratio) or convergence excess (high AC/A ratio). There are a wide range of symptoms reported in patients with abnormal accommodative convergence mechanism which 
are; blurred vision, diplopia, ocular discomfort during or immediately following near work, frontal headache, nausea, sleepiness, loss of concentration, heavy lid sensation, general fatigue and 'pulling' sensation of the eyes. All these symptoms thus negatively affect the overall activity of life of the child especially with respect to school and work performance

Many children who have reading problems or who are learning disabled or dyslexic have accommodative and vergence problem ${ }^{8.910}$. This therefore emphasizes the need to establish whether the AC/A ratios through +1.00DS and -1.00DS are related such that either of the two could be utilized as a tool in determining the gradient AC/A ratio of patients.

\section{MATERIALS AND METHODS}

Fifty healthy pupils of the Abia State University staff school were the subjects for the study. This sample size was arrived at after initial screening procedures. These procedures involved careful case history to rule out pathology (both ocular and systemic), and those on medication that could affect the study. Other tests include visual acuity, pinhole acuity (if the naked visual acuity is worse than 6/9), and external examination, cover and uncover test (to rule out strabismus) and opthalmoscopy.

In the data collection procedures, the refractive status of the subjects was determined, and those with ametropia corrected before the near phoria was determined with the subjective best visual acuity (BVA) lenses in place. The Von Graeffe method of phoria measurement was used ${ }^{11 .}$ The reduced Snellen vertical line of letters was used as target at a distance of $40 \mathrm{~cm}$. The prisms before the eyes were $15^{æ}$ Base-in before the right eye and $6^{æ}$ Base-up before the left eye. The patient would report two targets - one up and to the right and the other target down and displaced to the left. The prism base before the right eye, which is the measuring prism was slowly reduced until the patient reported a vertical alignment of the targets. If the residual prism before the right eye is 0 , the condition is orthophoria; if the prism base is in, the condition is exophoria to the amount indicate on the prism scale; if the prism base is out, the condition is esophoria to the amount indicated. The phoria was again taken through a +1.00DS and a 1.000DS over and above the subjective best visual acuity (B.V.A.) lenses. The change in phoria brought about by the change in stimulus to accommodation gave the value of the gradient AC/A ratio.

The normal range of $\mathrm{AC} / \mathrm{A}$ ratio for this study is $4 / 1$ to $6 / 1$ according to Grosvenor ${ }^{3}$. Values lower than $4 / 1$ would be considered low, while values higher than $6 / 1$ would be considered high. The Ztest at 0.05 level of significance was used to test for significant difference between the AC/A ratio through +1.00DS and through -1.00DS

\section{RESULTS}

Data were categorized under +1.00DS and -1.00DS for low, normal, and high AC/A ratios for the different percentage frequencies and represented in figure 1 . Through $+1.00 \mathrm{DS}, 68 \%$ of the subjects had low AC/A ratio $(30 \%$ had $2 / 1$, and $38 \%$ had 3/1), $26 \%$ had normal AC/A ratio (14\% had $4 / 1,8 \%$ had $5 / 1$, and $4 \%$ had $6 / 1$ ) and $6 \%$ had high AC/Aratio of 7/1.

Through $-1.00 \mathrm{DS}, 34 \%$ had low AC/A ratio (6\% had $1 / 1,18 \%$ had $2 / 1$ and $10 \%$ had $3 / 1), 52 \%$ had normal AC/A ratio (26\% had 4/1, $14 \%$ had 5/1, and $12 \%$ had 6/1) and 14\% had high AC/A ratio (10\% had $7 / 1$, and $4 \%$ had $8 / 1$ ).

\section{DISCUSSION}

Fifty primary school pupils between the ages of six to twelve years were used for the study. The mean AC/A ratio through +1.00DS was 3.4 $\pm 1.4 / 1$ and through $i ̈ 1.00 \mathrm{DS}$ was $4.2 \pm 2.0 / 1$. The range used for normal AC/A ration was $4 / 1$ to $6 / 1^{3}$. The percentage frequency of magnitude of $\mathrm{AC} / \mathrm{A}$ ratio through $+1.00 \mathrm{DS}$ was $68 \%, 26 \%$ and $6 \%$ for low, normal and high AC/A ratios respectively. While that through $-1.00 \mathrm{DS}$ was $34 \%, 52 \%$ and $14 \%$ for low, normal and high AC/A ratios respectively (fig1). The percentage of subjects with low AC/A ratio through both $+1.00 \mathrm{DS}(68 \%)$ and $-1.00 \mathrm{DS}$ (34\%) was found to be remarkable. Convergence insufficiency, which has low AC/A ratio as one of its clinical features, has been reported to be common among school age children ${ }^{12}$.

The mean AC/Aratio through +1.00DS (3.4/1) was lower than through -1.00DS (4.2/1). This difference was found to be significant using the two tailed Z-test at 0.05 level of significance $\left(\mathrm{Z}_{\text {cal }}-2.52\right.$ did not lie within \pm 1.96 ). It is recommended that borderline patients should have their gradient AC/A ratio checked through the two lenses for accurate diagnosis and management. 


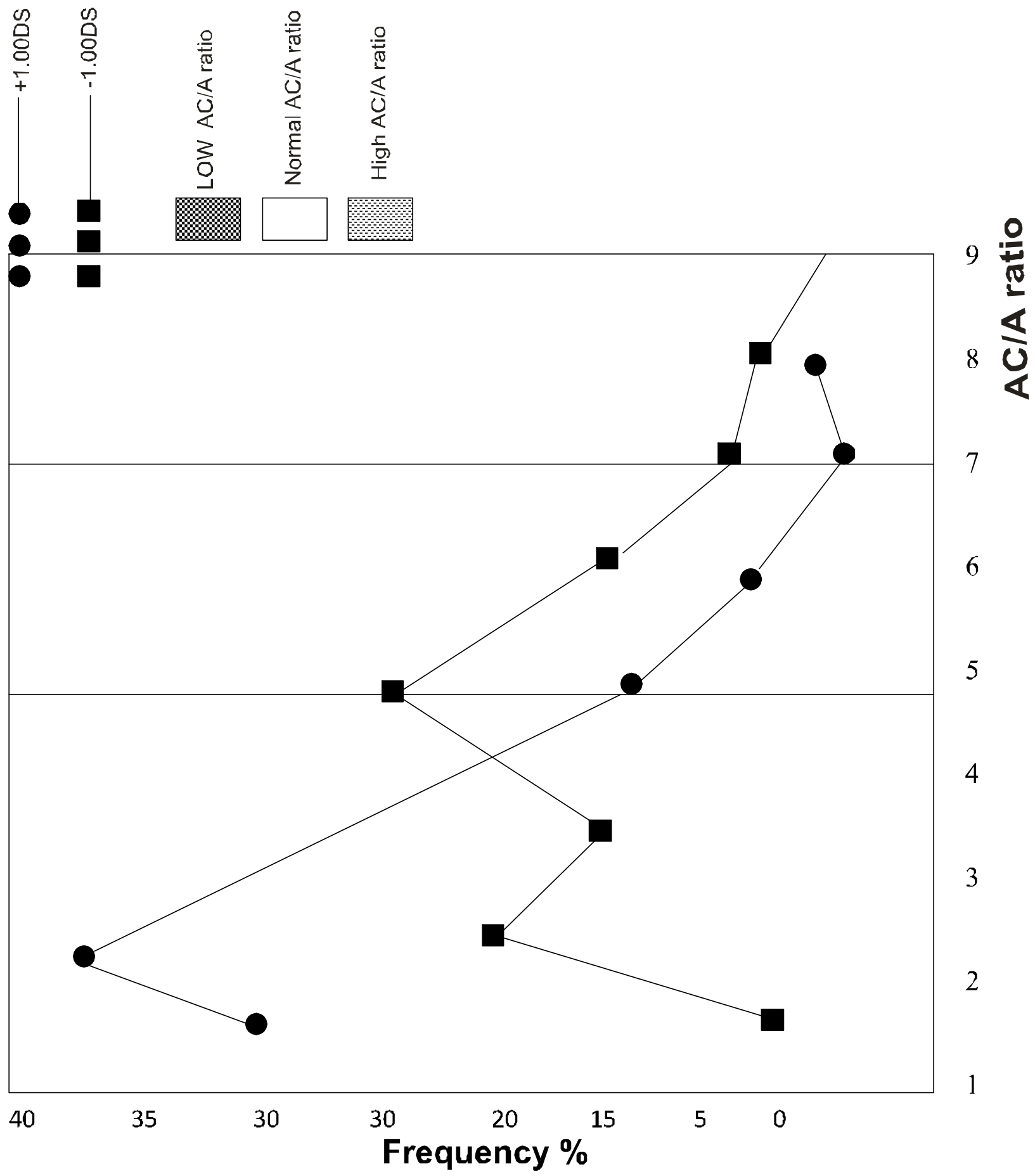

Fig 1:AC/a ratio percentage frequency through + 1.00DS and-1.00DS 


\section{RE FER E N C E S}

1. Babara, C., Sheilla, A. B. and Melvin, L. R. (1997): Dictionary of eye Terminology. $3^{\text {rd }}$ Edn. Triad Publishing Company, Gainesville, Florida, 666pp.

2. Kanski, J. J. (1994): Clinical Ophthalmology. $3^{\text {rd }}$ Edn. Butterworth-Heinemann, Oxford, $514 \mathrm{pp}$.

3. Grosvenor, T. (1996): Primary Eye care Optometry. $3^{\text {rd }}$ Edn. Butterworth-Heinemann, Oxford, 605pp.

4. David, B. E. (1997): Clinical procedures in Primary Eye Care Optometry. $3^{\text {rd }}$ Edn, Butterworth-Heinemann, Oxford, 230pp.

5. Pickwell, L. D. (1997): Binocular vision anomalies - Investigation and treatment. $3^{\text {rd }}$ Edn. Butterworth-Heinemann, Oxford, 250pp.

6. Stidwell, D. (1990): Orthoptic Assessment and management. $3^{\text {rd }}$ Edn. Blackwell Scientific Publications, Oxford, U.K., 30pp.

7. Ciuffreda, K. J. (2002): The scientific basis for and Efficacy of Optometric Vision Therapy in non-strabismic accommodative and vergence disorders. J. Am. Optom. Assoc, 73:725-54.

8. Eames, T. H. (1984): Low Fusional Convergence as a factor in reading disability. Am. J. Ophthalmol, 17:709-10.

9 Stein, J. F., Riddel, P. M. and Fowler, S. (1988): Disordered vergence control in dyslexic children. Br. J. Ophthalmol, 72: 162-6.

10. Buzelli, A. R. (1991): Stereopsis, accommodative and vergence facility. Do they relate to dyslexia? J. Optom. Vis Sci, 68:8426.

11. Borish, I. M. (1975): Photometry in: Clinical Refraction. $3^{\text {rd }}$ Edn. The Professional Press. Inc, 1381pp.

12. Borsting, E., Rouse, M. W., Deland, D. N., Hovelt, S., Kimura, O., Park, M. and Stephens, B. (2003): Association of symptoms and convergence and accommodative insufficiency in school age children. J. Am. Optom. Assoc, 74:25-34. 